\title{
The Hardware Failure and Correction Loss of Short- segment Pedicle Screw Fixation Combined With Transforaminal Interbody Fusion in Treatment of Unstable Thoracolumbar Burst Fracture: Retrospective Study in Vietnam
}

Ngoc Quyen Nguyen ( $\nabla$ bsquyenptcs108@gmail.com )

108 Military Central Hospital https://orcid.org/0000-0001-7114-4157

Trong Hau Phan

108 Military Central Hospital

Van Hong Vu

108 Military Central Hospital

\section{Research Article}

Keywords: Thoracolumbar burst fracture, Short-segment fixation, Transforaminal interbody fusion, Hardware failure, Correction loss

Posted Date: December 9th, 2021

DOI: https://doi.org/10.21203/rs.3.rs-1141848/v1

License: @ (i) This work is licensed under a Creative Commons Attribution 4.0 International License. Read Full License 


\section{Abstract}

Background: Correction loss and hardware failure of short segment posterior pedicle screw fixation in treatment of thoracolumbar unstable burst fracture have been remaining a main concern. Several authors have introduced the procedures to solve these limitations including transforaminal interbody fusion (TIF). The purposes of this study were to evaluate the progressive kyphosis and implant failure of shortsegment pedicle screw fixation combined with transforaminal interbody fusion in treatment of unstable thoracolumbar burst fracture.

Methods: The retrospective study were enrolled in the patients with isolated unstable thoracolumbar burst fractures, Denis type IIB who were treated by posterior short fixation with TIF between January 2013 to January 2017. Patients were followed up for a minimum of one and half year. For evaluation of correction loss, \% loss of anterior vertebral body heights (\%AVB), vertebral kyphotic angle (VA) and regional kyphotic angle (RA) were collected preoperatively, postoperatively and at final follow-up. The hardware failure was assessed on radiological images at last follow-up.

Results: There were 36 patients who met the inclusion criteria with a mean follow-up duration of 53 months. The mean correction loss of \%AVB, VA and, RA were $10.2 \%, 2.9^{\circ}$ and $5.6^{\circ}$, respectively. There were 6 patients (16.7\%) with hardware failure at final follow-up.

Conclusions: Short-segment posterior pedicle screw fixation with TIF using bone chip graft hasn't prevented completely the hardware failure and progressive kyphosis in treatment of unstable thoracolumbar burst fracture.

\section{Background}

Thoracolumbar burst fractures are defined as a spinal injury which results from axial compression with rupture of the anterior and medial structures of the vertebral body, with retropulsion of a bone fragment into the spinal canal and an increase in the interpedicular distance. According to Denis' classification for thoracolumbar burst fracture, the most common type was Denis type B [1]. It is still controversial about the optimal management for thoracolumbar burst fracture [2]. The short-segment posterior pedicle screw fixation still has been considered as a preferred option because it can reduce the blood loss, preserving segmental motion with an acceptable anatomic and functional outcome. However, loss of kyphotic corrections and high rate of hardware failure due to lack of the anterior column supporting have been knowing the main disadvantages of this short spinal fixation [3]. Several procedures aiming to reinforce the anterior column have been introduced to solve limitations of short-segmental posterior pedicle screw fixation including TIF [4, 5]. In Vietnam, the TIF with bone chip graft has been applying for treatment of unstable thoracolumbar burst fracture in order to prevent the limitations of short posterior fixation. However, to the best of our knowledge, there have been no report about the efficacy of posterior shortpedicle screw fixation with TIF using bone chip graft in treatment of unstable thoracolumbar burst 
fracture. This study aims to evaluate the hardware failure and correction loss of this surgical procedure for treatment of unstable thoracolumbar burst fracture in Vietnamese patients.

\section{Methods}

\section{Patient selection}

From Jan 2013 to Jan 2017, 40 consecutive patients who were operated by using posterior shortsegment pedicle screw fixation and TIF. All patients had a single level thoracolumbar burst fracture of Denis type IIB. Among 40 patients, 2 patients with quality of plain radiograph were not sufficient for analysis and 2 cases did not come for re-examination at final follow-up. Finally, a total of 36 patients have been enrolled in this study (Fig. 1).

This study was approved by our institution review board and informed consent was obtained from all patients.

\section{The surgical indications}

The patients who had one or more of the following: 1. Presence of neurological involvement caused by the fracture; 2. Computed tomography (CT) scanning of the affected level showed more than $50 \%$ spinal canal compromise; 3 . $\geq 50 \%$ loss of anterior vertebral height [6-8]; 4. Vertebral kyphosis angle $>30^{\circ}[7]$ were proceed this surgical method

All patients were evaluated using load sharing classification (LSC) [9] and underwent posterior shortsegment pedicle screw fixation with TIF.

\section{Surgical technique}

The patient was placed in prone position on a radiolucent table. The fractured vertebral body was identified by using fluoroscopy. Midline conventional longitudinal spinal incision was routinely used to expose one level above and below the fractured vertebra. Subperiosteal dissection was carried out with an electric cutter until the facet joints on both sides were visualized. Pedicle screws were inserted into vertebral body at 1 level below and above the affected level without insertion of the pedicle screw at the vertebral fracture. The screws of both sides were distracted axially with contoured longitudinal rods to restore the segmental height and realign the spinal columns and to perform indirectly the reduction of the retropulsed fragment. Then exposure of one transforaminal zone of the affected level was done using Kerrison rongeurs, to remove a part of the lamina and facet joint until the nerve root and thecal sac are revealed. Epidural veins and radicular veins were cauterized with bipolar forceps to avoid massive bleeding. Then, the thecal sac and nerve root were gently retracted, and the adjacent intervertebral disc was completely removed.

If the patient had neurologic deficit, and/or the stenotic degree of the spinal canal was more than $50 \%$ of its normal value, the retropulsed fragment of the fractured vertebral body was hammered anteriorly back 
into the vertebral body by using an 'L' shape dissector.

After that, the local bone graft was packed into the intervertebral space. If local bone was not enough, additional allograft or autograft from iliac bone was used. Decompression procedure was done with recheck of all the neural elements involved. A drain was placed, then wound were closed in standard fashion.

\section{Radiological evaluation}

All the patients were taken plain radiography preoperatively, postoperatively and at final follow-up. Evaluation of the plain radiograph included measurements of \% AVB and VA and RA. The RA of fractured segment was measured as the angle between the superior endplate of the upper adjacent vertebra and the inferior endplate of the lower adjacent vertebrae by the Cobb method [10] (Fig. 2A). VA was measured as the angle between a line drawn parallel to the superior endplate and a line drawn parallel to the inferior endplate of the fracture vertebra (Fig. 2A). Anterior body height of the injured and the non-injured adjacent vertebrae above and below were measured on the lateral X-ray film, and \% AVB was calculated as the anterior height of the fracture vertebra divided by the mean of the anterior height of the adjacent two vertebrae using the formula \% AVB $=100-2 b /(a+c) 100$ which was adopted by Mumford et al.[11]: The anterior vertebral body height of the proximal vertebra is marked as a; the anterior vertebral body height of fractured vertebra is marked as $b$; and $c$ is the anterior vertebral body height of the distal vertebra (Fig. 2B).

Fusion was defined based on the criteria of Bridwell [12] that was identified by using CT scan taken at the final follow-up. The hardware failure was defined as a correction loss of more than $10^{\circ}$ of the RA values at the final follow-up, compared tothat of the immediate postoperative period, and/or pedicle screw(s), and/or rod(s) breakage.

\section{Statistic analyses}

SPSS 20.0 was used for statistical analysis. The paired t-test was used to analyze differences between preoperative, postoperative, and final follow-up radiographic data within each group. The Mann-Whitney test was used to analyze numerical data between the 2 groups. The level of statistical significance was set at $p<0.05$.

\section{Results}

\section{Demographic data}

A final total of 36 patients were enrolled in this study. The age range was 18 to 59 years old (mean 47 years old), with 20 males and 16 females. The mean follow-up duration was 53 months (range, 17-73 months). The affected levels were T12, L1 and L2 in 4 patients, 22 patients, 10 patients, respectively. More than two third of participants had history of falling from height (28 cases), the others main source of trauma were traffic accidents ( 4 cases); sport accidents ( 3 cases), and direct trauma ( 01 case). All the 
cases were type IIB according to the Denis classification system. The mean LSC was 6.8 (range, 5-9) (Table 1).

Table 1

Demographic data

\begin{tabular}{|c|c|c|c|c|}
\hline \multirow[b]{2}{*}{ Parameters } & \multicolumn{3}{|c|}{ Hardware failure (no. [\%]) } & \multirow[t]{2}{*}{ Total } \\
\hline & No & Yes & $\mathrm{p}$ value & \\
\hline No. & & & & 36 \\
\hline Follow up months & $51.0 \pm 17.1$ & $64.8 \pm 8.3$ & 0.078 & $53.3 \pm 16.7$ \\
\hline Age & $47.8 \pm 12$ & $41.7 \pm 9$ & 0.143 & $46.8 \pm 11.7$ \\
\hline \multicolumn{5}{|l|}{ Gender (\%) } \\
\hline Female & $16(44.4)$ & $0(0)$ & & $16(44.4)$ \\
\hline Male & $14(38.9)$ & $6(16.7)$ & & $20(55.6)$ \\
\hline \multicolumn{5}{|c|}{ The reasons of trauma } \\
\hline Fall from height & $23(63.9)$ & $5(13.9)$ & & $28(77.8)$ \\
\hline Traffic accident & $4(11.1)$ & $0(0)$ & & $4(11.1)$ \\
\hline Sport accident & $3(8.3)$ & $0(0)$ & & $3(8.3)$ \\
\hline Direct trauma & $0(0)$ & $1(2.8)$ & & $1(2.8)$ \\
\hline \multicolumn{5}{|l|}{ Fracture level } \\
\hline T12 & $4(11.1)$ & $0(0)$ & & $4(11.1)$ \\
\hline L1 & $17(47.2)$ & $5(13.9)$ & & $22(61.1)$ \\
\hline L2 & $9(25)$ & $1(2.8)$ & & $10(27.8)$ \\
\hline LSC & $6.7 \pm 1.1$ & $7.0 \pm 0.6$ & 0.493 & $6.8 \pm 1.1$ \\
\hline
\end{tabular}

\section{Radiological outcomes}

Table 2 shows the mean \%AVB, VA, RA, and the loss of kyphotic correction. All of the parameters were significantly improved after surgery. Nevertheless, they were decreased considerably with statistical significance at the final observation when compared with that of the postoperation. The mean correction loss of the \%AVB, VA, RA were $10.2 \%, 2.9^{\circ}, 5.6^{\circ}$ at the last follow-up, respectively. 
Table 2

Correction loss of kyphotic deformity at final follow - up

\begin{tabular}{|c|c|c|c|c|}
\hline Parameters & Pre-operative & Immediately post-operative & Final follow-up & Correction loss \\
\hline$\% A V B$ & 49.1 & $17.3^{\star}$ & $27.5+, \star \star$ & 10.2 \\
\hline $\operatorname{VA}\left({ }^{\circ}\right)$ & 24.6 & $11.5^{\star}$ & $14.4^{+, \star \star \star}$ & 2.9 \\
\hline $\mathrm{RA}\left({ }^{\circ}\right)$ & 19.7 & $8.5^{\star}$ & $14.1^{+, \star \star}$ & 5.6 \\
\hline
\end{tabular}

Incidence of harware failure was $16.7 \%(6 / 36)$. There were no patients who demonstrated screw loosening or loss of RA $>10^{0}$ (Table 3 ).

Table 3

The prevalence of hardware failure

\begin{tabular}{|c|c|c|}
\hline Hardware failure & No $(\%)$ & Total (\%) \\
\hline- & $30(83.3)$ & 83.3 \\
\hline + Screw breakage below fracture level & $2(5.6)$ & 16.7 \\
\hline Screw breakage above fracture level & $3(8.3)$ & \\
\hline Rod pull-out of above screw head & $1(2.8)$ & \\
\hline Loss of regional kyphosis angle $>10^{0}$ & 0 & \\
\hline Screw loosening & 0 & \\
\hline
\end{tabular}

According to Bridwell's fusion grade using CT, six cases of hardware failure were classified as fusion grade I, 3 cases; grade II, 2 cases; and grade III, 01 case (Table 4).

Table 4

CT grading of the interbody fusion based on Bridwell's criteria

\begin{tabular}{|lll|}
\hline Fusion grade & No (\%) & Numbers of cases of implant failure \\
\hline I & $23(63.9)$ & 3 cases \\
\hline II & $10(27.8)$ & 2 cases \\
III & $3(8.3)$ & 1 case \\
IV & 0 & 0 \\
\hline
\end{tabular}




\section{Discussion}

The traditional posterior surgery for treatment of the thoracolumbar burst fractures is a relatively a straightforward surgical technique but can only give indirect reduction of the fractured vertebral body, and the means of supporting the anterior column are limited $[13,14]$. Several studies has reported the loss of reduction caused by insufficient anterior column support with or without hardware failure was not uncommon $[15,16]$. Posterior spinal fixation approach can be divided into long-segment fixation (fixation more than two upper and lower vertebral fracture), and short-segment fixation (involving one level above and one below the fractured level).

It has proved that long segment fixation is strong enough to stabilize the fractured spine. However, the fused spine becomes less flexible and more susceptible to low back pain. Meanwhile, short-segment posterior fixation is thought to stabilize the fractured vertebra efficiently while saving motion segments in compared to long segment fixation. However, previous studies reported the earlier implant failure and correction loss as the most important disadvantages of this method [3, 17]. McLain et al. [3] reported $52.5 \%$ of implant failure in their study on short-segment fixation in treatment of thoracolumbar burst fracture. Thus, several techniques with anterior column intervention have been suggested as alternative methods to overcome this limitation. The kyphotic deformity was corrected to a considerable extent with posterior fixation and indirect reduction. With the help of intact anterior longitudinal ligament and annulus of interverebral disc, it is easy to correct the kyphoctic deformity of the fracture spine by posterior pedicle screw devices. How to deal with a large amount of bone defect inside the fractured vertebral body which is a main problem. The large bone defect created inside the fractured vertebra after height restoration of injuried vertebral body had been speculated to be the most essential cause of that correction loss. Moreover, the restoration of the intervertebral disc height may also contribute to the loss of kyphotic correction [18]. Beside that an usual laminectomy for the management of thoracolumbar burst fractures might lead to further spinal instability [19]. It was hypothesized that the TIF might solve those problems by minimizing the correction loss. TIF technique removes a part of articular process at one side, and almost all spinal structures can be preserved. By impact bone graft into the intervertebral space and even into the vertebral body through the fractured endplate after disc excision, it is possible to reconstruct the anterior and middle columns of the fracture spine and stabilize of the instablility of fracured vertebral body. Therefore, it may provide additional stability with short pedicle screw fixation. Wang et al. [5] recorded the favorable outcomes without significant correction loss and hardware failure when combined short-segment pedicle screw fixation with TIF using granulated bone graft and cage for treatment of thoracolumbar unstable burst fracture. However, the efficacy of TIF using bone chip graft has not been reported.

Here, we reported the radiculogical outcomes of short posterior fixation with TIF using bone chip graft in the treatment of thoracolumbar unstable burst fracture, Denis type IIB, and with the mean follow-up was 53 months. The correction of kyphotic deformity which was evaluated by \%AVB, VA and RA, was gradually lost and the average of correction loss was $10.2 \%, 2.9^{\circ}$, and $5.6^{\circ}$, respectively. Hardware failure occurred in 6 patients (16.7\%) during the follow-up period, of which, 3 cases of screw breakage above 
fracture level, 2 cases of screw breakage below fracture level, and one case with rod pull-out of screw head (Fig. 3). These outcomes showed that the TIF with bone chip graft did not completely prevent the correction loss and hardware failure of short segment pedicle screw fixation for the treatment of thoracolumbar burst fracture. But, 4 out of 6 cases with hardware failures had good interbody fusion with Bridwell grade I or II, and all of such cases did not need to perform the revision surgery (Fig. 4). In order to prevent the hardware failure and correction loss of short-segment fixation in treatment of thoracolumbar unstable burst fracture, several additional procedures have been introducing but no ideal techniques have proved [5]. Vu et al. [20] reported the radiological outcomes of the short posterior fixation and fusion for 31 patients with thoracolumbar burst fracture. They recorded $29 \%$ of the implant failure while the mean correction loss of RA and VA were $2.3^{\circ}$ and $7^{\circ}$, respectively. Liao et al. [21] reported the outcomes of 27 patients with thoracolumbar burst fracture who were treated a six pedicle screw construct (group 1), and twenty-nine patients underwent a four screw construct and fractured vertebra augmentation by injectable calcium sulfate/phosphate cement (group 2). The authors found the rate of hardware failure and the mean correction loss of \%AVB, RA were $11.1 \%, 8.9^{\circ}, 4.2^{\circ}$ in group 1 and were $27.6 \%, 13.3^{\circ}, 6.3^{\circ}$ in group 2 , respectively.

The role of posterior/posterolateral fusion in minimization of late complications of short-segment fixation in treatment of thoracolumnbar burst fracture has been unclear and several authors suggested that posterior/posterolateral fusion would not be necessary when treating thoracolumbar burst fractures with a posterior pedicle screw fixation [22-24]. Futhermore, we also wanted to accurately evaluate the outcomes of TIF with bone chip graft in prevention of poor radiological outcomes of short posterior instrumentation so the posterior/posterolateral fusion was not added in these case series. However, we suppose that the posterior/posterolateral fusion in combination with TIF may provide the better prevention of the disadvantages of the short posterior fixation. Nevertheless, based on this study, we think that removal of implant after achievement of solid interbody fusion might be better than supplementation of the posterior/posterolateral fusion in term of reducing the hardware failure of short segment posterior instrumentation, particularly in related to the implant failure of distal unfused spine level because it also restores simultaneously the motion of unfused spine by the removal of instrumentation. But, we need to do futher studies to confirm these issues. There have been reports that the posterior short-segment pedicle screw fixation combined with intermediate screw at the fractured vertebrae can help improve biomechanical stablility and achieve better reduction; cause less correction loss, and fewer hardware failures [25]. However, Liao et al. [21] reported 3 cases of the implant failure after using six-screw construct in treatment of 27 patients with thoracolumbar unstable burst fracture. Thus, we suppose that this technique combined with TIF using bone chip graft may get better outcomes. However futher research is needed on this issue.

A limitation of this study was patients who involved in the research were all classified as Denis type IIB of a thoracolumbar burst fracture. It is robust result of the study, on the one hand, by the Denis type IIB classified as one of the most common type of fractures. And on another hand, there was lack of comparation of the hardware failure and progressive kyphosis between the two groups of LSC because 
of small sample size. In addition, this study did not present a ideal method in prevention of late complication of short-segment pedicle screw fixation in treatment of thoracolumbar burst fracture. Nevetheless, this is the first report of these complications of short posterior fixation with TIF using bone chip graft for treatment of thoracolumbar unstable burst fracture in Vietnam.

\section{Conclusions}

TIF with bone chip graft hasn't solved completely the disadvantages of short-segmental pedicle screw fixation in treatment of thoracolumbar unstable burst fracture. The correction loss after surgical management following this technique in long-term follow-up is still happened and the incidence of hardware failure was $16.7 \%$.

\section{List Of Abbreviations}

Transforaminal interbody fusion (TIF), \% loss of anterior vertebral body heights (\%AVB), vertebral kyphotic angle (VA), regional kyphotic angle (RA), Computed tomography (CT), load sharing classification (LSC).

\section{Declarations}

\section{Ethical approval and consent to participate}

This retrospective study was approved by our hospital institutional review board before its commencement.

\section{Consent for publication}

Not applicable.

\section{Availability of data and materials:}

The data used to support the findings of this study are available from the corresponding author upon request.

\section{Conflicts of interest}

The authors declare that they have no conflicts of interest.

\section{Authors' contributions}

NQN designed the research, perfomed operation, acquired data and analyzed data and drafted the manuscript and revised manuscript for important intellectual content. THP designed the research, performed operation and revised manuscript, VHV acquired data and analyzed data and drafted the manuscript. All authors read and approved the final manuscript. 


\section{Funding}

None.

\section{Acknowledgements}

None.

\section{References}

1. Denis $F$. The three column spine and its significance in the classification of acute thoracolumbar spinal injuries. Spine (Phila Pa 1976). 1983;8(8):817-31. doi:10.1097/00007632-198311000-00003.

2. Alpantaki K, Bano A, Pasku D, Mavrogenis AF, Papagelopoulos PJ, Sapkas GS, et al. Thoracolumbar burst fractures: a systematic review of management. Orthopedics. 2010;33(6):422-9. doi:10.3928/01477447-20100429-24.

3. McLain RF, Sparling E, Benson DR. Early failure of short-segment pedicle instrumentation for thoracolumbar fractures. A preliminary report. J Bone Joint Surg Am. 1993;75(2):162-7. doi:10.2106/00004623-199302000-00002.

4. Schmid R, Krappinger D, Blauth M, Kathrein A. Mid-term results of PLIF/TLIF in trauma. Eur spine J. 2011;20(3):395-402. doi:10.1007/s00586-010-1615-3.

5. Wang L, Li J, Wang H, Yang Q, Lv D, Zhang W, et al. Posterior short segment pedicle screw fixation and TLIF for the treatment of unstable thoracolumbar/lumbar fracture. BMC Musculoskelet Disord. 2014;15:40. doi:10.1186/1471-2474-15-40.

6. Chadha M, Bahadur R. Steffee variable screw placement system in the management of unstable thoracolumbar fractures: a Third World experience. Injury. 1998;29(10):737-42. doi:10.1016/s00201383(98)00173-9.

7. Mikles MR, Stchur RP, Graziano GP. Posterior instrumentation for thoracolumbar fractures. J Am Acad Orthop Surg. 2004;12(6):424-435. doi:10.5435/00124635-200411000-00007.

8. Domenicucci M, Preite R, Ramieri A, Ciappetta P, Delfini R, Romanini L. Thoracolumbar fractures without neurosurgical involvement: surgical or conservative treatment? J Neurosurg Sci. 1996;40(1):1-10.

9. McCormack T, Karaikovic E, Gaines RW. The load sharing classification of spine fractures. Spine (Phila Pa 1976). 1994;19(15):1741-1744. doi:10.1097/00007632-199408000-00014.

10. Farcy JP, Weidenbaum M, Glassman SD. Sagittal index in management of thoracolumbar burst fractures. Spine (Phila Pa 1976). 1990;15(9):958-965. doi:10.1097/00007632-199009000-00022.

11. Mumford J, Weinstein JN, Spratt KF, Goel VK. Thoracolumbar burst fractures. The clinical efficacy and outcome of nonoperative management. Spine (Phila Pa 1976). 1993;18(8):955-70.

12. Bridwell KH, Lenke LG, McEnery KW, Baldus C, Blanke K. Anterior fresh frozen structural allografts in the thoracic and lumbar spine. Do they work if combined with posterior fusion and instrumentation 
in adult patients with kyphosis or anterior column defects? Spine (Phila Pa 1976). 1995;20(12):1410-8.

13. Been HD, Bouma GJ. Comparison of two types of surgery for thoraco-lumbar burst fractures: combined anterior and posterior stabilisation vs. posterior instrumentation only. Acta Neurochir (Wien). 1999;141(4):349-357. doi:10.1007/s007010050310.

14. Hitchon PW, Torner J, Eichholz KM, Beeler SN. Comparison of anterolateral and posterior approaches in the management of thoracolumbar burst fractures. J Neurosurg Spine. 2006;5(2):117-125. doi:10.3171/spi.2006.5.2.117.

15. Alanay A, Acaroğlu E, Yazici M, Aksoy C, Surat A. The effect of transpedicular intracorporeal grafting in the treatment of thoracolumbar burst fractures on canal remodeling. Eur spine J. 2001;10(6):512516. doi:10.1007/s005860100305.

16. Knop C, Fabian HF, Bastian L, Blauth M. Late results of thoracolumbar fractures after posterior instrumentation and transpedicular bone grafting. Spine (Phila Pa 1976). 2001;26(1):88-99. doi:10.1097/00007632-200101010-00016.

17. Müller U, Berlemann U, Sledge J, Schwarzenbach O. Treatment of thoracolumbar burst fractures without neurologic deficit by indirect reduction and posterior instrumentation: bisegmental stabilization with monosegmental fusion. Eur spine J. 1999;8(4):284-289. doi:10.1007/s005860050175.

18. Kerttula LI, Serlo WS, Tervonen OA, Pääkkö EL, Vanharanta H V. Post-traumatic findings of the spine after earlier vertebral fracture in young patients: clinical and MRI study. Spine (Phila Pa 1976). 2000;25(9):1104-1108. doi:10.1097/00007632-200005010-00011.

19. Verlaan JJ, Diekerhof CH, Buskens E, van der Tweel I, Verbout AJ, Dhert WJA, et al. Surgical treatment of traumatic fractures of the thoracic and lumbar spine: a systematic review of the literature on techniques, complications, and outcome. Spine (Phila Pa 1976). 22004;29(7):803-814. doi:10.1097/01.brs.0000116990.31984.a9.

20. Vu TT, Morishita Y, Yugue I, Hayashi T, Maeda T, Shiba K. Radiological Outcome of Short Segment Posterior Instrumentation and Fusion for Thoracolumbar Burst Fractures. Asian Spine J. 22015;9(3):427-432. doi:10.4184/asj.2015.9.3.427.

21. Liao J-C, Fan K-F. Posterior short-segment fixation in thoracolumbar unstable burst fractures Transpedicular grafting or six-screw construct? Clin Neurol Neurosurg. 2017;153:56-63. doi:10.1016/j.clineuro.2016.12.011.

22. Jindal N, Sankhala SS, Bachhal V. The role of fusion in the management of burst fractures of the thoracolumbar spine treated by short segment pedicle screw fixation: a prospective randomised trial. J Bone Joint Surg Br. 2012;94(8):1101-1106. doi:10.1302/0301-620X.94B8.28311.

23. Dai L-Y, Jiang L-S, Jiang S-D. Posterior short-segment fixation with or without fusion for thoracolumbar burst fractures. a five to seven-year prospective randomized study. J Bone Joint Surg Am. 2009;91(5):1033-1041. doi:10.2106/JBJS.H.00510. 
24. Wang S-T, Ma H-L, Liu C-L, Yu W-K, Chang M-C, Chen T-H. Is fusion necessary for surgically treated burst fractures of the thoracolumbar and lumbar spine?: a prospective, randomized study. Spine (Phila Pa 1976). 2006;31(23):264652.doi:10.1097/01.brs.0000244555.28310.40.

25. Li K, Zhang W, Liu D, Xu H, Geng W, Luo D, et al. Pedicle screw fixation combined with intermediate screw at the fracture level for treatment of thoracolumbar fractures: A meta-analysis. Medicine (Baltimore). 2016;95(33):e4574. doi:10.1097/MD.0000000000004574.

\section{Figures}

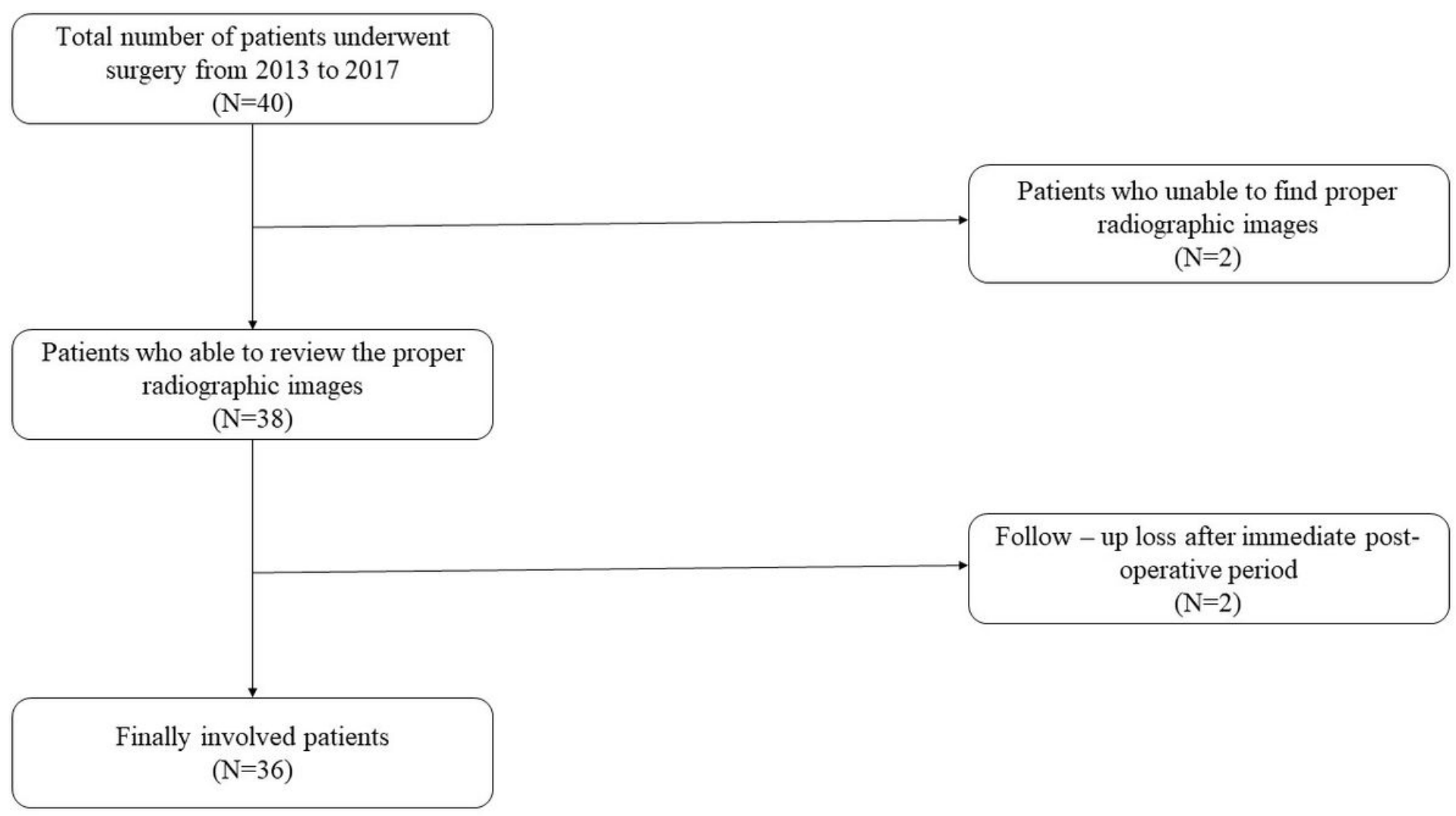

\section{Figure 1}

Schematic diagram of patients' selection 


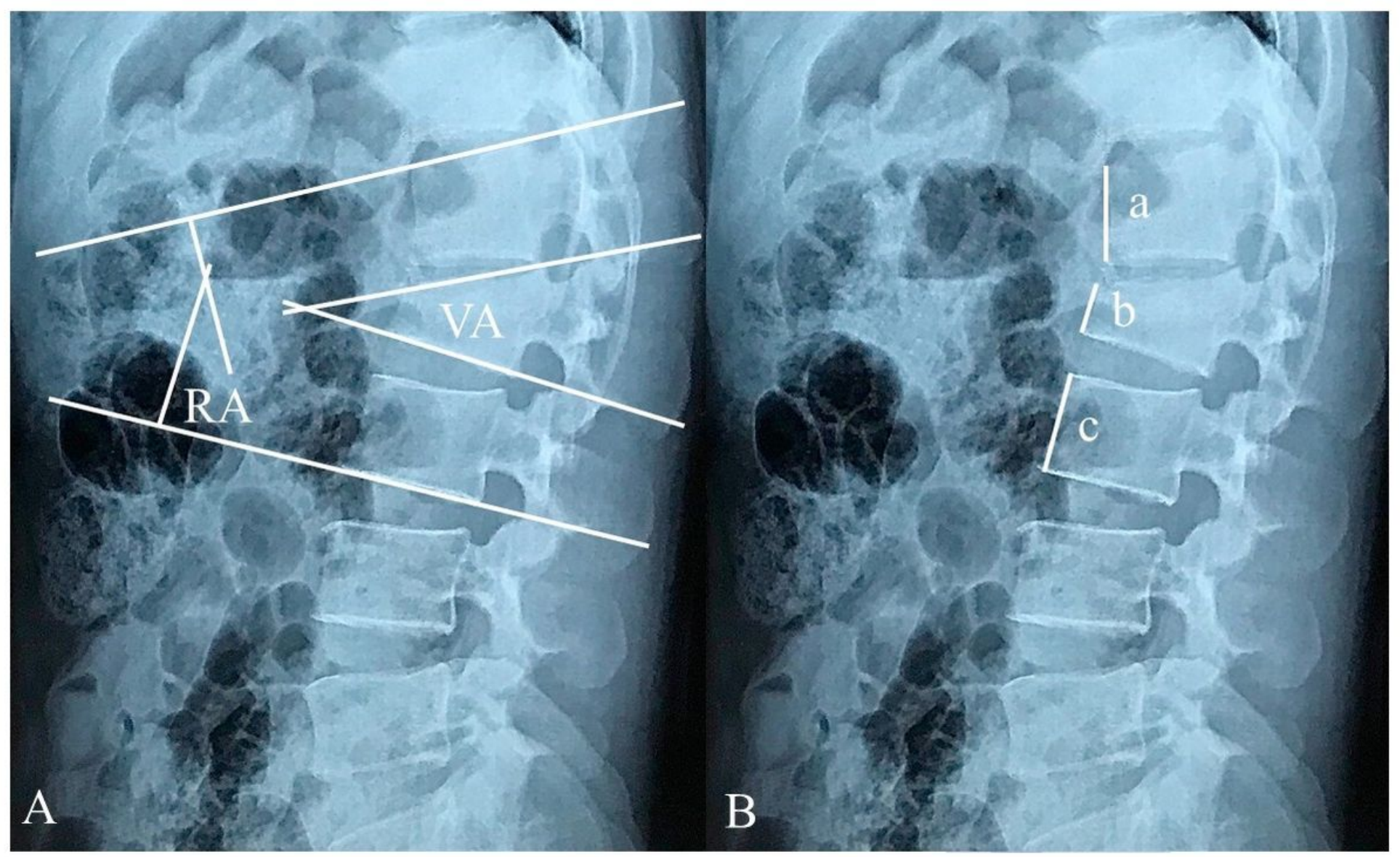

Figure 2

Parameters on plain X-rays: (Fig. 2A): Regional kyphotic angle (RA), Vertebral kyphotic angle (VA); (Fig. 2B): anterior edge height of vertebra above the fractured vertebra (a), anterior edge height of fractured vertebra (b), anterior edge height of vertebra below the fractured vertebra (c). 


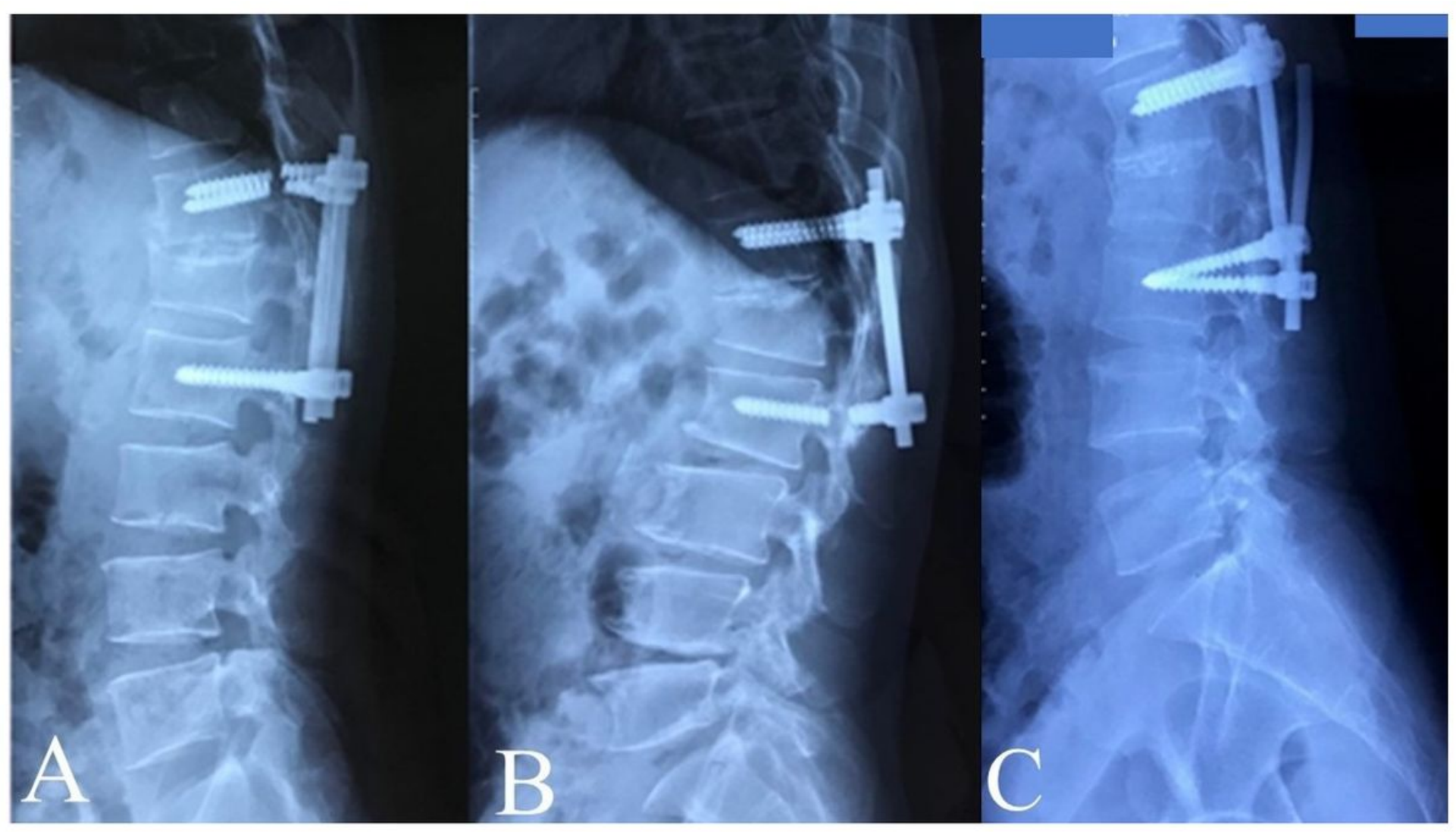

\section{Figure 3}

The implant failure: (Fig. 3A): breakage of pedicle screws above fracture level; (Fig. 3B): breakage of pedicle screws below fracture level; (Fig. 3C): rod pull out of pedicle screw head.

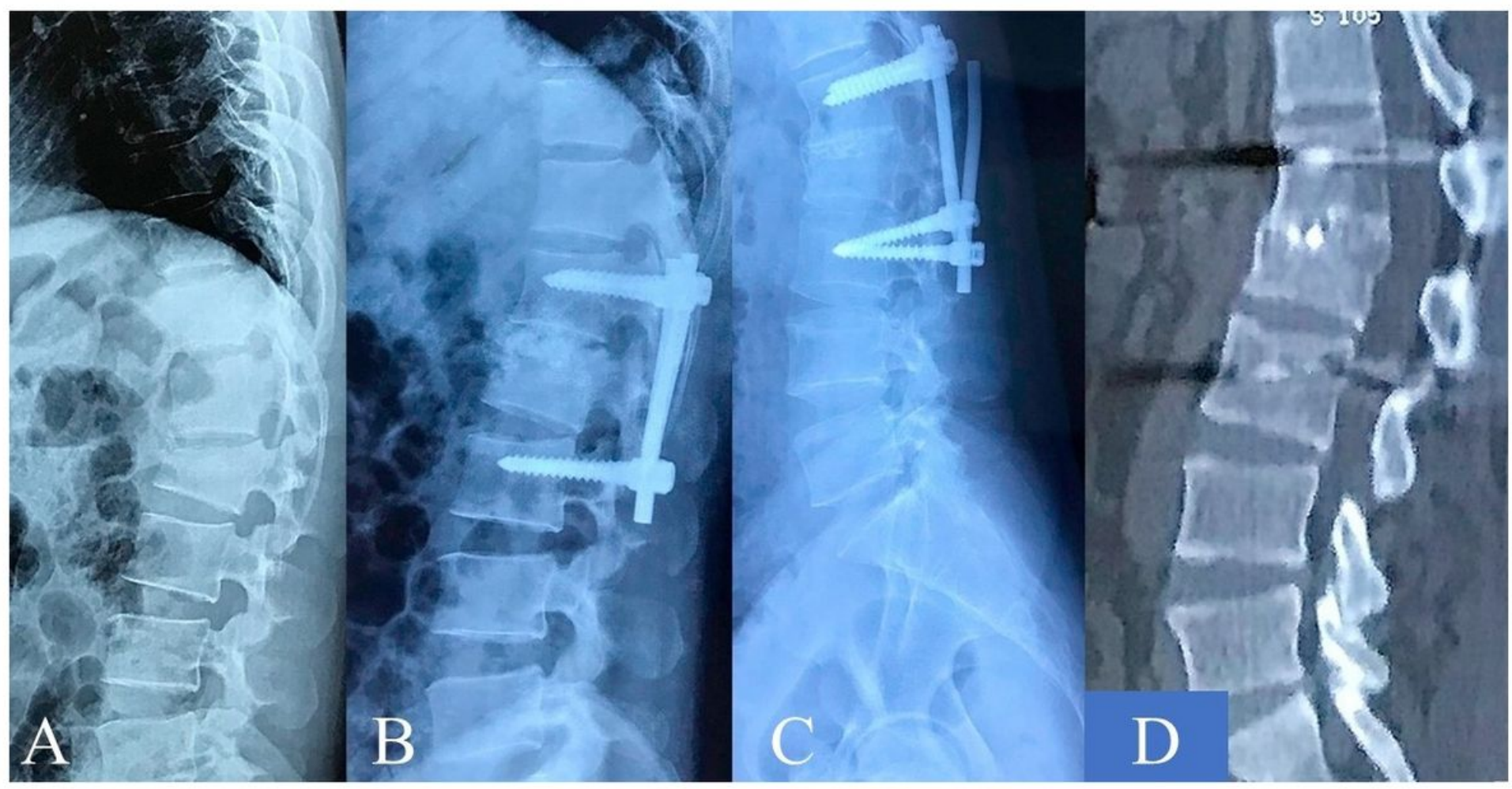




\section{Figure 4}

Good bone union in the patient with hardware failure: (Fig. 4A): Preoperative Xray; (Fig. 4B): Postoperative Xray; (Fig. 4C): Final follow-up Xray with hardware failure; (Fig. 4D): Sagittal CT at last follow-up with good bone union. 